\title{
Williams-Beuren Syndrome Presenting as Pulmonary Edema with Pleural Effusion: A New Pulmonary Manifestation of Elastin Vasculopathy
}

Fadi Al Khazzam, Ashraf Gad, Muhammad Dilawar

\begin{abstract}
Introduction: Williams-Beuren syndrome (WBS) is a gene deletion disorder characterized by distinct facial features, cardiovascular anomalies, and intellectual disability. Many genes are involved in WBS, of which the elastin (ELN) gene deletion is almost present in all cases. Limited data exist about pulmonary diseases in children with WBS. Furthermore, pleural effusion (PE) has not been reported in these patients.
\end{abstract}

Case Presentation: A term, small-for-gestational-age (SGA) male Caucasian newborn presented with respiratory distress shortly after vaginal birth. A chest radiograph showed significant pulmonary edema with bilateral pleural effusion. A 2D Echocardiogram demonstrated supravalvular aortic stenosis and branch pulmonary stenosis suspecting WBS. A genetic evaluation revealed an interstitial $1.5 \mathrm{Mb}$ deletion in the long arm of chromosome 7 involving band q11.23 confirming the diagnosis of WBS. The child underwent surgical repair at 4 months for age due to cardiac disease progression.

Conclusions: An unexplained finding of pulmonary edema and $P E$ in a newborn can be associated with genetic disorders and warrants investigation for WBS, especially in SGA newborns.

\section{Key words}

Williams-Beuren syndrome, ELN, Elastin, Williams syndrome, pleural effusion, microdeletion, supravalvular aortic stenosis, and branch pulmonary artery stenosis

\section{Background:}

Williams-Beuren Syndrome (WBS) is a contiguous gene deletion disorder that involves the chromosomal region $7 q 11.23$ (1). WBS affects about 1 in 10000 to 23500 live births, depending on the population $(2,3)$. The deleted chromosomal region in WBS involves many genes, particularly the elastin $(E L N)$ gene, which is present in the majority of cases of WBS (1).

The clinical manifestations of WBS are quite variable and comprise distinct facial features, cardiovascular anomalies, growth failure, transient hypercalcemia, hypothyroidism, musculoskeletal defects, genitourinary, stellate iris pattern, hypotonia, and peculiar neurodevelopmental and behavioral profile (2-10). Early diagnosis of patients with WBS, especially in the neonatal period, can be

Readers can also follow NEONATOLOGY TODAY via our Twitter Feed @NEOTODAY challenging due to the sporadic nature of the disorder; also important physical features can be overlooked, resulting in devastating outcomes including sudden death (11).

Pleural effusion (PE) results from disruption of the pleural liquid turnover in the pleural space. Although PE is a clinical feature of some genetic syndromes and chromosomal abnormalities (1214 ), it is not associated with WBS. Additionally, limited data have been published on the involvement of pulmonary disease in patients with WBS $(15,16)$.

\section{"The clinical manifestations of WBS are quite variable and comprise distinct facial features, cardiovascular anomalies, growth failure, transient hypercalcemia, hypothyroidism, musculoskeletal defects, genitourinary, stellate iris pattern, hypotonia, and peculiar neurodevelopmental and behavioral profile (2-10)."}

In this report, we present a case of a male infant with WBS born with pulmonary edema with PE and progressive supravalvular aortic stenosis (SVAS) and branch pulmonary artery stenosis (PAS). We review the relevant literature concerning the presentation of WBS in the neonatal period, mainly due to pulmonary disease. To our knowledge, there have been no other published reports similar to this unusual presentation.

\section{Case Presentation:}

A Serbian male infant was born at 37 weeks' gestation via induced vaginal delivery to a 31-year-old caucasian mother. The mother is otherwise healthy; her firstborn female child was $4 \mathrm{~kg}$ at term birth. Antenatal laboratory screening was unremarkable except for a positive GBS on the vaginal swab for which she received adequate treatment with Penicillin G. In the third trimester, fetal ultrasonography indicated fetal growth restriction with a low enddiastolic flow and abnormal pulsatility index on the umbilical artery Doppler. On admission, her membranes were intact, and the fetal heart rate tracing was category-1. After 20 hours of labor induction, including a 9-hour second stage, a healthy baby was born vigorous, the amniotic fluid was clear. The baby required only routine care. Apgar scores were 9 and 10 at 1 and 5 minutes, respectively. Birth weight was $2.35 \mathrm{~kg}$ (5th percentile), head circumference $33 \mathrm{~cm}$ (35th percentile), and length $45 \mathrm{~cm}$ (5th percentile). The newborn was transferred to the postnatal ward to room in with his mother. The placental histopathologic examination revealed a small placenta, weight $350 \mathrm{~g}$ (<3rd percentile), and a marginally inserted 3-vessel umbilical cord. 

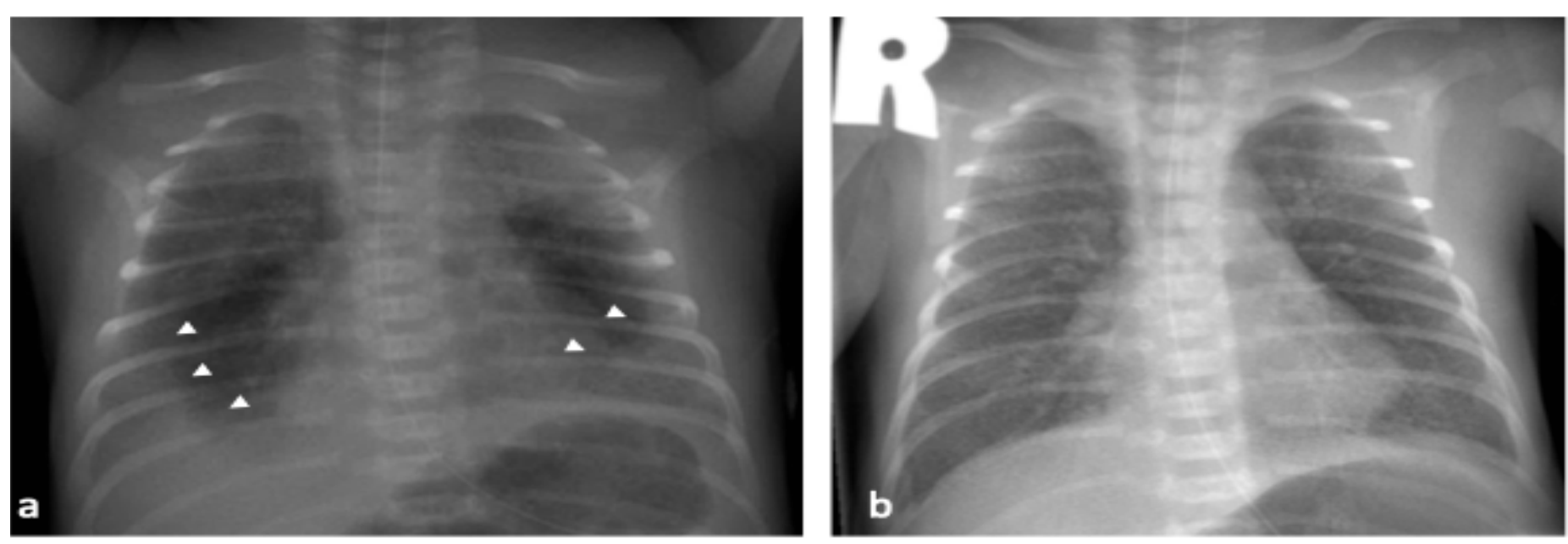

(Figure 1a and 1b): Chest x-ray on admission (Figure 1a) demonstrates mild lung hyperinflation, diffuse interstitial edema and opacification, and bilateral pleural effusion (arrowheads). Chest x-ray 2 days later (Figure 1b) while on CPAP demonstrates inflated lungs, interstitial edema with fluid in the interlobar fissure, and resolution of the pleural effusion.

In the postnatal ward, the baby developed tachypnea and circumoral cyanosis at four hours of age; therefore, he was transferred to the neonatal intensive care unit (NICU) for further management.

Physical examination upon admission to the NICU revealed tachypnea with subcostal retractions. The cardiac exam revealed a grade 2/6 systolic ejection murmur at the left lower sternal border. Other features included epicanthal folds, upturned nose, and wide mouth; the rest of the clinical examination was unremarkable. Chest X-ray (Figure 1a) revealed significant bilateral lung opacification indicating alveolar and interstitial edema, hyperinflation, and bilateral pleural effusion.

\section{"Genetic consultation was sought because of the unexplained finding of pulmonary edema and PE. Microarray analyses revealed an interstitial deletion of the long arm of chromosome 7 involving band q11.23."}

The baby required continuous positive airway pressure (CPAP) support for two days and a nasal cannula for an additional day. He was started on ampicillin and amikacin antibiotic on admission for suspected sepsis and continued for 7 days, provided the chest $\mathrm{X}$-ray findings. Chest X-ray (Figure $1 \mathrm{~b}$ ) repeated after two days demonstrated persistent hyperinflation (on CPAP), intersti- tial edema, and appearance of fluid in the interlobar fissure, and resolution of the pleural effusion.

Sepsis evaluation revealed normal results, including a negative blood culture. Serum electrolytes showed a corrected serum calcium level of $2.41 \mathrm{mmol} / \mathrm{L}(9.7 \mathrm{mg} / \mathrm{dl})$.

A 2D echocardiogram (echo) done on the second day of life revealed an aneurysmal atrial septum with a small fenestrated atrial septal defect with left-to-right shunting, a small-mid muscular ventricular septal defect with left-to-right shunting, patent descending aorta with a peak gradient of $14 \mathrm{mmHg}$.

Genetic consultation was sought because of the unexplained finding of pulmonary edema and PE. Microarray analyses revealed an interstitial deletion of the long arm of chromosome 7 involving band q11.23. The deleted region is $\sim 1.5 \mathrm{Mb}$ in size and includes 24 genes, including ELN, LIMK1, BAZ1B, CLIP2, GTF2IRD, NSUN5, CLDN4, EIF4H, LAT2, MLXIPL, TBL2, WBSCR18, WBSCR22, WBSCR27, confirming the diagnosis of WBS. The chromosomal microarray study done on both parents was normal. The baby was discharged home at one week of age in a stable condition.

A follow-up echo study done at 4 weeks of age revealed mild SVAS with a peak gradient of $34 \mathrm{mmHg}$, and moderate bilateral branch PAS, peak gradients 40 to $50 \mathrm{mmHg}$, and normal biventricular size and function. The study was repeated at 10 weeks of age (Figure $2 a \& 2 b$ ) revealed progression of the SVAS; diameter $5.1 \mathrm{~mm}, Z$ score -3.2 , and branch PAS, right pulmonary artery; diameter $2.9 \mathrm{~mm}$, $Z$ score -2.8 , and left pulmonary artery; $4.6 \mathrm{~mm}$, $Z$ score -0.43 , with a peak gradient of $81 \mathrm{mmHg}$, and $56 \mathrm{mmHg}$, respectively. The descending aorta with flow acceleration showed a peak gradient of $30 \mathrm{mmHg}$ and moderate left ventricular hyper-

NEONATOLOGY TODAY is interested in publishing manuscripts from Neonatologists, Fellows, NNPs and those involved in caring for neonates on case studies, research results, hospital news, meeting announcements, and other pertinent topics.

Please submit your manuscript to: LomaLindaPublishingCompany@gmail.com 


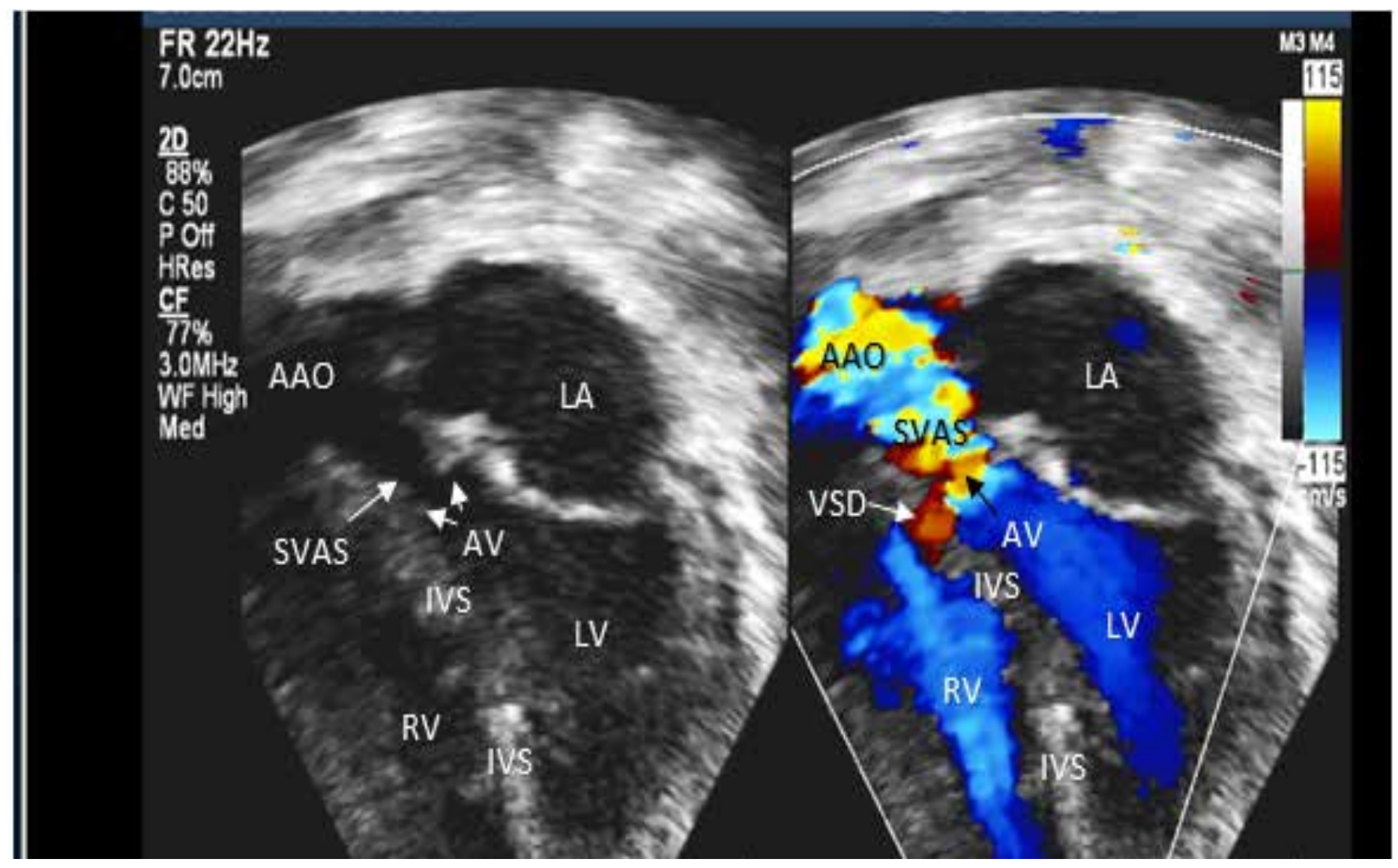

Figure 2a. A 2D echo with color Doppler depicting Supravalvular aortic stenosis (SVAS) and ventricular septal defect (VSD) in apical 3-chamber view. AV; Aortic valve, AAO; Ascending Aorta, IVS; interventricular septum, RV; right ventricle, LA; left atrium, LV; left ventricle.

trophy.

A computed tomography (CT) scan of the chest done at three months of age confirmed the latter cardiac findings and also revealed narrowing in the sub-isthmus part of the descending aorta but without evidence of focal coarctation.

\section{"The exact cause of pulmonary edema and PE in our patient is unclear; however, it is notable that the disruption of the pleural liquid turnover process of any etiology results in pleural fluid accumulation."}

At 4 months of age, the infant underwent open-heart surgery for Brom aortoplasty of the SAVS with pulmonary homograft patch augmentation of both PAs. Postoperatively, the baby developed reactive hypertension requiring treatment with multiple antihypertensives medications; he was discharged home on oral furosemide and propranolol. He was also started on prophylaxis for subacute bacterial endocarditis and continued to have high normal serum calcium levels and adequate weight gain. He was also

started on levothyroxine treatment for hypothyroidism.

\section{Discussion}

WBS is a gene deletion disorder that involves the $7 q 11.23$ regions (1). Although up to 28 deleted genes have been described in this disorder, the ELN gene mutation is the most predominant one. This particular gene deletion results in elastin vasculopathy characterized by elastosis and disorganization of the elastic lamellae in the affected tissue $(6,17)$. Although ELN gene deletion is peculiarly related to the cardiovascular disease often described in patients with WBS, the role other deleted genes play in the pathology and clinical manifestations of WBS is hardly defined (18).

Elastin is expressed in multiple cell types in the lung, including pleural mesothelial cells, smooth muscle cells in airways and blood vessels, endothelial cells, and interstitial fibroblasts (19). Elastin protein integrates with fibrillin-containing microfibrils in the extracellular matrix to form the elastic fibers that contribute to the physical property of these tissues (19).

The exact cause of pulmonary edema and PE in our patient is unclear; however, it is notable that the disruption of the pleural liquid turnover process of any etiology results in pleural fluid accumulation. pleural liquid normally originates from the high-pressure systemic blood vessels in the parietal pleural membranes and drains into the lymphatic stomata located in the submesothelial connective tissue of the parietal pleura. We hypothesize that elastosis in the submesothelial connective tissue or in the vascular 


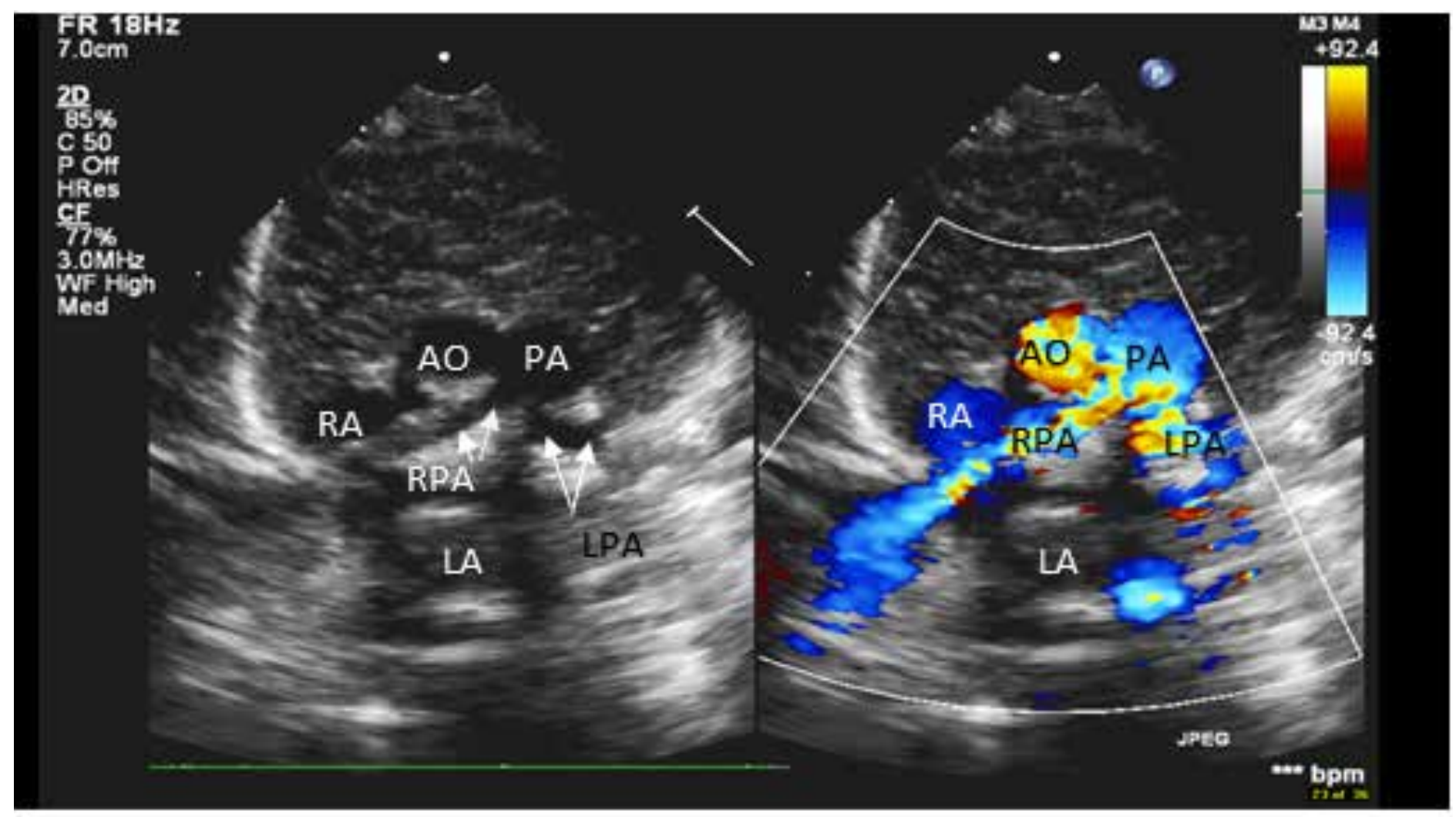

Figure 2b. A 2D echo with color Doppler depicting pulmonary artery (PA), right pulmonary artery (RPA), and left pulmonary artery (LPA) in high parasternal view. AO; Aorta, RA; right atrium, LA; left atrium

wall increases the microvascular pressure and results in either altered pleural liquid secretion or impaired drainage, or both (20). Additionally, blockage of the lymphatic stomata by a similar mechanism affects liquid absorption. Alveolar and interstitial edema, consequently, PE can also arise if the elastin layer in the visceral pleura, and the alveolar or vascular wall is defective. Speculatively, this can result in either leakage of the fetal alveolar fluid into the pleural space, impaired clearance of the fetal fluid from the alveoli and the interstitium, or through both mechanisms (21). Although PE due to congenital lymphatic malformation (chylothorax) is associated with specific genetic and chromosomal disorders such as Gorham-Stout, Optiz G/BBB, Hennekam, Milroy syndromes, Trisomy 21, Turner, and noon syndrome (12-14), our patient is the first reported description of PE in a case of WBS.

Other respiratory conditions reported in patients with WBS are congenital lobar emphysema (CLE). Walsh et al. published the case of a preterm male infant who had suffered respiratory distress syndrome until day 25 of life when he developed CLE, requiring left upper lobectomy at six weeks of age. Wong et al. also reported a 2-month-old infant found to have CLE in the right middle lobe during his preoperative cardiac workup for surgical repair; a bronchoscopy demonstrated a small, collapsed right middle lobe bronchial orifice. Impaired lung elastin production has been suggested to play the primary role in the pathogeneses of CLE in both patients $(15,16)$.

Studies have shown that loss of elastin fiber integrity is a trigger of inflammation and tissue injury in certain diseases such as chronic obstructive pulmonary disease, emphysema, and cutis laxa (2124). In the adult literature, Wojcik et al. reported a case of severe bullous emphysema in a male adult who was later confirmed to have WBS (26). Another case of WBS for a young adult man who had paraseptal emphysema incidentally found on chest CT. To further assess the association of pulmonary manifestations in WBS, Wan et al. studied a cohort of 16 nonsmoker adolescents and young adults with WBS. They found higher respiratory symptoms in WBS subjects despite nonsignificant spirometric abnormalities compared to controls (26).

The penetrance and severity of SVAS and total cardiovascular disease in WBS subjects are more common among male subjects, as described by Sadler et al., possibly due to hormonal effect (27). In her study, male gender and a low body mass index increased the likelihood of an earlier diagnosis of WBS (27). Consistent with the previous study conclusion, the abnormal finding of chest X-ray in our patient, in addition to growth restriction, led us to entertain a genetic diagnosis. Although chest CT did not delineate a discrete coarctation in our patient, the subisthmus narrowing of the aorta is usually regarded as an atypical form of coarctation, particularly in this disorder, resulting in the so-called middle aortic syndrome. Such a syndrome can rapidly progress to a severe form of focal coarctation or diffuse narrowing, as describe by Kammache et al. and Hall et al. $(28,29)$. Moreover, lifelong cardiac follow up is essential in the patient because of the risk of developing vasculopathy or arterial hypertension (8).

Finally, the upper respiratory features of this disorder include changed quality of voice, which may advance to upper airway obstruction. Stridor associated with subglottic cyst has been reported in WBS (30). Koren et al. and Vaux et al. published the cases of bilateral vocal cord paralysis revealed on an endoscopic exam 
of 2 separate newborns who later required tracheostomy $(31,32)$. A third infant presented with noisy breathing in the neonatal period and developed significant stridor in the second year of life (32). The findings of harsh, hoarse, or brassy quality of voice changes in WBS patients can be explained by impaired elastogenesis in the lamina propria of the vocal cords, as illustrated by heterozygous Eln deletions (Eln +/-) experiment in mice (33). However, the mechanism of paralysis of the vocal cords in these children needs further explanation.

\section{Conclusion:}

WBS is associated with severe short and long term morbidity and mortality in children. Unexplained findings of PE after birth can be a manifestation of elastin vasculopathy disorder such as WBS, especially in the presence of additional abnormal features such as growth restriction and cardiac murmur. Therefore, it is imperative to exercise vigilance in order to diagnose WBS in the neonatal period.

\section{Authors' Contributions:}

Dr. Al Khzzam and Dr. Gad have an equal share in drafting this manuscript. They both reviewed the literature and equally contributed to drafting, reviewing, and editing the final version.

\section{References}

1. Merla G, Brunetti-Pierri N, Micale L, Fusco C. Copy number variants at Williams-Beuren syndrome $7 q 11.23$ region. Hum Genet. 2010 Jul;128(1):3-26.

2. Pober BR. Williams-Beuren syndrome. N Engl J Med. 2010 Jan 21;362(3):239-52. doi: 10.1056/NEJMra0903074. Review.

3. Yau EK, Lo IF, Lam ST. Williams-Beuren syndrome in the Hong Kong Chinese population: retrospective study. Hong Kong Med J. 2004 Feb;10(1):22-7.

4. Ji C, Yao D, Chen W, Li M, Zhao Z. Adaptive behavior in Chinese children with Williams syndrome. BMC Pediatr. 2014 Apr 4;14:90.

5. Morris CA, Mervis CB. Williams syndrome and related disorders. Annu Rev Genomics Hum Genet. 2000;1:461-84. Review.

6. Honjo RS, Dutra RL, Furusawa EA, Zanardo EA, Costa LS, Kulikowski LD, Bertola DR, Kim CA. Williams-Beuren Syndrome: A Clinical Study of 55 Brazilian Patients and the Diagnostic Use of MLPA. Biomed Res Int. 2015;2015:903175.

7. Eronen M, Peippo M, Hiippala A, Raatikka M, Arvio M, Johansson $R$, Kähkönen $M$. Cardiovascular manifestations in 75 patients with Williams syndrome. J Med Genet.2002 Aug;39(8):554-8.

8. Yao D, Ji C, Chen W, Li M, Zhao ZY. Physical growth and development characteristics of children with Williams syndrome aged 0-24 months in Zhejiang Province. J Pediatr Endocrinol Metab. 2019 Mar 26;32(3):233-237. doi:10.1515/ jpem-2018-0185.

9. Pascual-Castroviejo I, Pascual-Pascual SI, Moreno Granado F, García-Guereta L, Gracia-Bouthelier R, Navarro Torres $M$, Delicado Navarro A, López-Pajares D, Palencia Luaces R. [Williams-Beuren syndrome: presentation of 82 cases]. An Pediatr (Barc). 2004 Jun;60(6):530-6. Spanish.

10. Viana $M M$, Frasson $M$, Galvão $H$, Leão $L L$, Stofanko $M$, Gonçalves-Dornelas $H$, da Silva Cunha P, Burle de Aguiar
MJ. Ocular Features in 16 Brazilian Patients with WilliamsBeuren Syndrome. Ophthalmic Genet. 2015;36(3):234-8.

11. Wang MS, Schinzel A, Kotzot D, Balmer D, Casey R, Chodirker BN, Gyftodimou J, Petersen MB, Lopez-Rangel E, Robinson WP. Molecular and clinical correlation study of Williams-Beuren syndrome: No evidence of molecular factors in the deletion region or imprinting affecting clinical outcome. Am J Med Genet. 1999 Sep 3;86(1):34-43.

12. Tutor JD. Chylothorax in infants and children. Pediatrics. 2014Apr;133(4):722-33. doi: 10.1542/peds.2013-2072. Epub 2014 Mar 31. Review.

13. Joyce S, Gordon K, Brice G, Ostergaard P, Nagaraja R, Short J, Moore S, Mortimer P, Mansour S. The lymphatic phenotype in Noonan and Cardiofaciocutaneous syndrome. Eur J Hum Genet. 2016 May;24(5):690-6.

14. Ebrahimi-Fakhari D, Freiman E, Wojcik MH, Krone K, Casey A, Winn AS, Roberts AE, Harper BD. Congenital Chylothorax as the Initial Presentation of PTPN11-Associated Noonan Syndrome. J Pediatr. 2017 Jun;185:248-248.e1. doi:10.1016/j.jpeds.2017.02.042. Epub 2017 Mar 28.

15. Walsh TA, Gopagondanahalli KR, Malhotra A. WilliamsBeuren Syndrome and Congenital Lobar Emphysema: Uncommon Association with Common Pathology? Case Rep Pediatr. 2017;2017:3480980.

16. Wong W., Fiorino E. A novel case report of congenital lobar emphysema in a patient with williams-beuren syndrome. Chest. 2012;142, article 1009A doi: 10.1378/ chest.1390068.

17. di Gioia CR, Ciallella C, d'Amati G, Parroni E, Nardone AM, Gallo P. Neonatal Williams syndrome presenting as an isolated supravalvular pulmonary stenosis. Arch Pathol Lab Med. 2003 Sep;127(9):e367-70.

18. Li DY, Toland AE, Boak BB, Atkinson DL, Ensing GJ, Morris $C A$, Keating MT. Elastin point mutations cause an obstructive vascular disease, supravalvular aortic stenosis. Hum Mol Genet. 1997 Jul;6(7):1021-8.

19. Mecham RP. Elastin in lung development and disease pathogenesis. Matrix Biol. 2018 Nov;73:6-20. doi: 10.1016/j. matbio.2018.01.005. Epub 2018 Jan 11. Review.

20. Broaddus VC, Wiener-Kronish JP, Staub NC. Clearance of lung edema into the pleural space of volume-loaded anesthetized sheep. J Appl Physiol (1985). 1990 Jun;68(6):262330.

21. Rennard SI, Jaurand MC, Bignon J, Kawanami O, Ferrans VJ, Davidson J, Crystal RG. Role of pleural mesothelial cells in the production of the submesothelial connective tissue matrix of lung. Am Rev Respir Dis. 1984 Aug;130(2):267-74.

22. Houghton AM, Quintero PA, Perkins DL, Kobayashi DK, Kelley DG, Marconcini LA, Mecham RP, Senior RM, Shapiro $S D$. Elastin fragments drive disease progression in a murine model of emphysema. J Clin Invest. 2006 Mar;116(3):753-9. Epub 2006 Feb 9.

23. Callewaert B, Renard M, Hucthagowder V, Albrecht B, Hausser I, Blair E, Dias C, Albino A, Wachi H, Sato F, Mecham $R P$, Loeys B, Coucke PJ, De Paepe A, Urban Z. New insights into the pathogenesis of autosomal-dominant cutis laxa with report of five ELN mutations. Hum Mutat. 2011 Apr;32(4):445-55.

24. Kelleher CM, Silverman EK, Broekelmann T, Litonjua AA, Hernandez M, Sylvia JS, Stoler J, Reilly JJ, Chapman HA, Speizer FE, Weiss ST, Mecham RP, Raby BA. A functional 
mutation in the terminal exon of elastin in severe, early-onset chronic obstructive pulmonary disease. Am J Respir Cell Mol Biol. 2005 Oct;33(4):355-62. Epub 2005 Aug 4.

25. Wojcik MH, Carmichael N, Bieber FR, Wiener DC, Madan $R$, Pober BR, Raby BA. A new diagnosis of Williams-Beuren syndrome in a 49-year-old man with severe bullous emphysema. Am J Med Genet A. 2017 Aug;173(8):2235-2239. doi:10.1002/ajmg.a.38289. Epub 2017 Jun 2.

26. Wan ES, Pober BR, Washko GR, Raby BA, Silverman EK. Pulmonary function and emphysema in Williams-Beuren syndrome. Am J Med Genet A. 2010 Mar;152A(3):653-6.

27. Sadler LS, Pober BR, Grandinetti A, Scheiber D, Fekete G, Sharma AN, Urbán Z. Differences by sex in cardiovascular disease in Williams syndrome. J Pediatr. 2001 Dec;139(6):849-53.

28. Kammache I, Acar P, Kreitmann B, Fraisse A. Williams-Beuren syndrome: an unusual cause of neonatal and infantile coarctation. J Thorac Cardiovasc Surg. 2010 Nov;140(5):e80-1.

29. Hall EK, Glatz J, Kaplan P, Kaplan BS, Hellinger J, Ernst L, Gaynor JW. A case report of rapid progressive coarctation and severe middle aortic syndrome in an infant with Williams syndrome. Congenit Heart Dis. 2009 Sep-Oct;4(5):373-7.i

30. Christoforidis A, Tsakalides $C$, Chatziavramidis A, Karagianni $P$, Dimitriadou $M$, Konstantinidis I. Sizeable acquired subglottic cyst in a baby with Williams-Beuren syndrome: association or coincidence? Gene. 2013 Oct 15;529(1):148-9.

31. Koren I, Kessel I, Rotschild A, Cohen-Kerem R. Bilateral vocal cord paralysis and hypothyroidism as presenting symptoms of Williams-Beuren syndrome: a case report. Int $\mathrm{J} \mathrm{Pe}$ diatr Otorhinolaryngol. 2015 Sep;79(9):1582-3.

33. Watts CR, Knutsen RH, Ciliberto C, Mecham RP. Evidence for heterozygous abnormalities of the elastin gene (ELN) affecting the quantity of vocal fold elastic fibers: a pilot study. $J$ Voice. 2011 Mar;25(2):e85-90.

The authors have no conflicts of interests to disclose.

NT

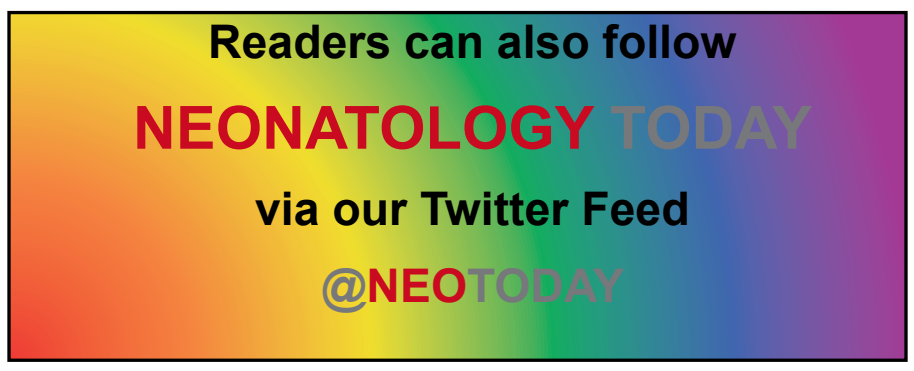

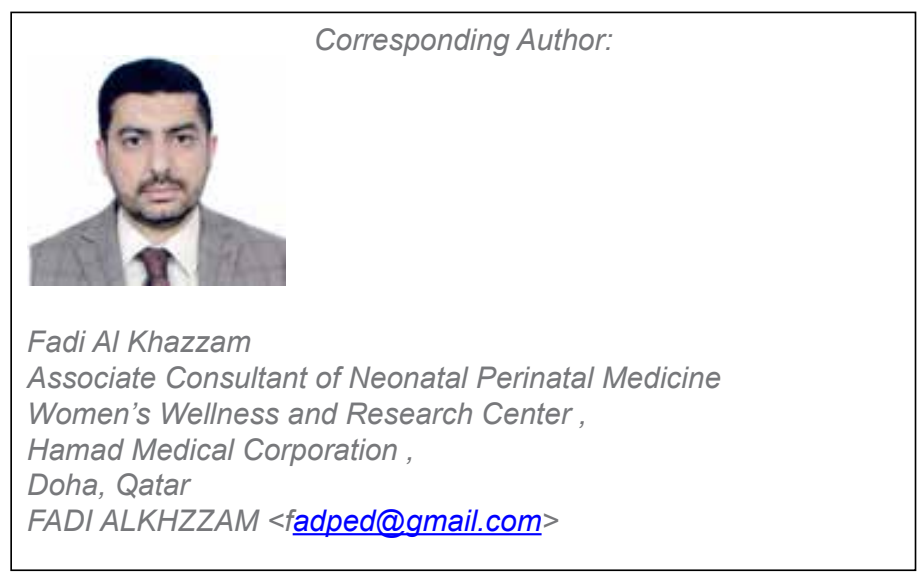

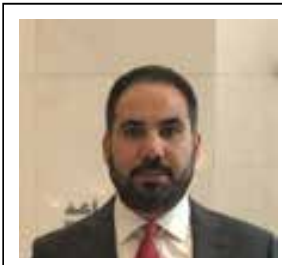

Ashraf Gad

Neonatal Perinatal Medicine

Women's Wellness and Research Center,

Hamad Medical Corporation,

Doha, Qatar

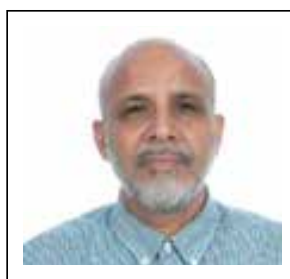

Muhammad Dilawar

Department of Pediatrics

Hamad Medical Corporation

Doha, Qatar

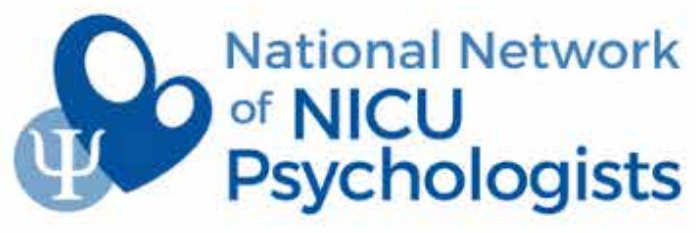

www.nationalperinatal.org/psychologists

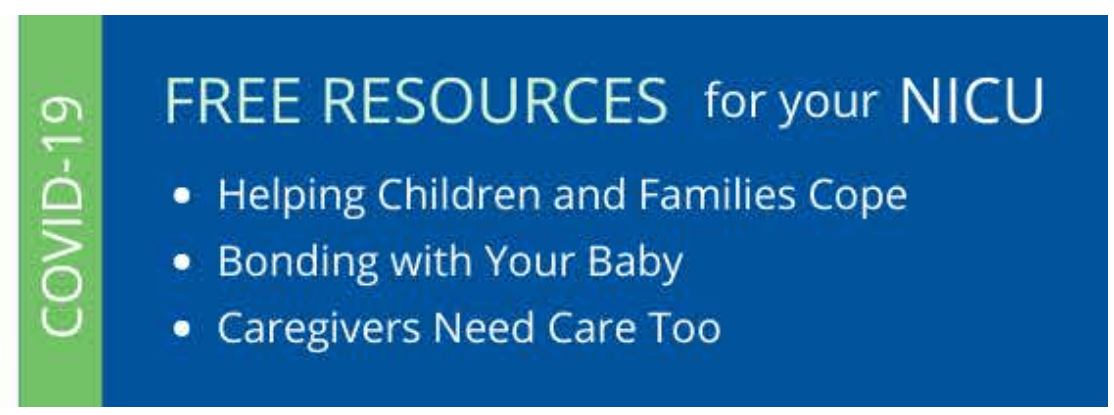

